\title{
Language Game as a Means of Creating Implicit Meanings
}

\author{
Berezhnykh Natalia ${ }^{1, *}$, Sivtseva Natalia $^{2}$, Skopintseva Tatiana ${ }^{1}$, and Sludneva Lyudmila ${ }^{1}$ \\ ${ }^{1}$ Irkutsk Transport University, Department of Foreign Languages, 15, Chernyshevsky st., 664074, Irkutsk, Russia, \\ ${ }^{2}$ National Research Technical University, Department of Applied Linguistics, 83, Lermontov st., 664074, Irkutsk, Russia
}

\begin{abstract}
This article presents a number of theoretical aspects of "implicit meanings" associated with their definition and reasons making communicators use indirect communication. A typical communicative situation is described in which speakers deliberately conceal the meaning. It is called a communicative triad and involves two types of addressees - "true addressee" and "unplanned participant" of communication. When considering a number of communicative situations of the triad, which are not directly intended to conceal information, one can note the analogy with the phenomenon of "language game", as one of its features is lack of rational grounds for its functioning. The production of implicit meanings based on the language game principle is described in the form of precedent texts inclusion, where the parameters of presence/absence of the precedent text significance for different categories of recipients, as well as the different participants' awareness of the factors and rules of the game are significant. There are two scenarios allowing participants to complicate the meaning, which correspond to the main game types distinguished in the game theory "game-competition" and "game-presentation". Besides, the authors analyze the use of specialized precedent phenomena, as well as simpler means of playing with the meaning based on the category of uncertainty.
\end{abstract}

\section{Introduction}

According to classical and modern scientific works on linguistics, rhetoric, literary criticism, cultural studies, poetics and semiotics, implicit meaning development is explained on the basis of language asymmetry principle (Ch. Bally, A.A. Potebnya, S.O. Kartsevsky), unique relevance and unlimited meaning variations (M.M. Bakhtin), its subjective inexpressibility, the "conflict of interpretations" (U. Eco). Currently, the problem of implicit meanings is being increasingly discussed in linguistics, however, there is neither common understanding of the character nor a systemic description of the linguistic mechanisms used to produce them. It should be noted that there are no well-defined parameters for differentiating the notions that are frequently used within the context of the problem in question - "implicit meanings", "semantic uncertainty", "semantic ambiguity", "semantic bivalence", "implicitness", "implied meaning", "text implication", etc. The facts mentioned above determine the relevance of this article. Besides, within the framework of the research implicit meanings are understood as a way of organizing the message based on various kinds of meaning transformations so that it (message/information) can be perceived by its recipient in a form and volume corresponding to the communicative intentions of its producent.

\section{Implicit Meanings and Their Interpretation. Language Game as a Pattern of Verbal Behaviour}

The range of issues concerning implicit meanings (sometimes they are referred to as hidden meanings) is discussed in the works of such Russian and foreign researchers as B.A. Larin, V.V. Vinogradov, I.R. Galperin, I.V.Arnold, N.D. Arutyunova, T.G. Vinokur, E.I. Shendels, N.Yu.Shvedova, A.I.Baranov, O.A.Bogatyrev, O.S.Sishchikov, L.V.Lisochenko. They recognize that implicit meanings can be found at all levels of the language structure and in various types of discourses (V.I. Karasik, D. Pehar, K.Hamilton). They are realized in communication strategies (T.A.Vorontsova, V.S. Pugach) and they determine the peculiarities of idiostyle (I.Yu. Oblachko). Besides, one of the characteristics of everyday conversational speech is abundance of implicit meanings [1].

One of the most well-known definitions of implicit meanings is given by A.A. Maslennikova, who believes that such meanings should include any meaning that is not expressed verbally, however, it is perceived by the addressee as an implied one and interpreted by him/her on the basis of his/her language competence, knowledge of the world and text indicators" [2]. The fact that implicit meanings are not expressed verbally does not mean that they can be understood as some content having no form [3]. The peculiarity of this type of meaning, as the researcher believes, is its development based on ...the

\footnotetext{
* Corresponding author: belkova-n@yandex.ru
} 
interaction between explicit meaning and the cumulative conditions of its manifestation [3].

Another definition represents implicit meanings as "... a part of the aggregate information with an inhomogeneous structure transmitted by an unrestricted text of a natural language; it is not manifested in the text explicitly but it coexists with implicitly expressed ... information. It is derived or can be derived from this text - regardless of its nature, relevance for a particular participant of communication and the addressee's "planning it out", as well as of the fact whether this information appears in the isolated text or only when the given text is included in some broader context" [4]. I.I. Prosvirkina introduces the metaphor-term "implicit meanings" and understands them as the lack of communicative linguistic and/or sociocultural competences necessary for understanding reported information [5].

The participants of communication are aware of their appeal to implicit meanings which is represented by a variety of cryptological communication systems. It is illustrated by numerous examples in the studies devoted to general and historical linguistics, semiotics, cultural studies, history of science, among them there is the language of VirgilMaro (5 AD), the cipher of Caesar ( $\mathrm{J}$. Vendryes, C. Hagège), Galilean's anagrams, palindrome texts, secret professional languages, literary "secret writing" (Aesop's language). Functioning of these systems is aimed at achieving specific goals in specific historical situations and is associated with several facts: need of secret means of communication during wars, conquering for scientific priority, protection of professional secrets, peculiar characteristics of mythological thinking, separation of the sphere of the sacred from that of the profane, overcoming censorship bans on free expression.

In the modern world, the communicants' implicit meanings needs are interpreted more widely and associated with obtaining social and political power [6], desire to protect institutional ideologies [7], maintaining a certain level of quality in the field of science [8], "linguistic self-defense" in totalitarian societies (A. Wierzbicka), providing adequate communication within separate discursive communities (J. Swales) and closed subcultures, necessity to follow social restrictions concerning the number of speech acts. The appeal to implicit meanings can be also understood as preventing the interference with the personal space, classified information protection, as well as craving for communicative leadership. When there is inconsistency between the categories of social and individual the production of implicit meanings is aimed at reducing cognitive dissonance $[9,10]$.

The ideas mentioned above allow concluding that the production of implicit meanings by speakers and writers is conditioned by definite goals; it is a motivated, mainly reflective type of speech behavior. However, according to the authors' observations, the production of implicit meanings may not have the indicated goals in some types of communicative situations. If a person does not have a deliberate intention to "hide some information", it allows drawing a number of analogies with the phenomenon of "language game", as one of its features is the lack of rational bases for its functioning [11], cf. also "the game is played by itself' [11].

The initial research of the notion of the game was conducted in the philosophical works by I. Kant and F. von Schiller, who pointed out the similarity between the game and artistic activity. Further, in the scientific literature on games theory, the close connection between game forms and various forms of human activity is emphasized and the game conception of culture is substantiated $[11,12]$. Studying the characteristics and peculiarities of the game, the researchers point out the possibility of its "live" within the framework of other, possible worlds, they write that it may be recognized as "a being" different from the ordinary life [12]. Another characteristics of the game is its existence within the certain limits of time, space and meaning outside the sphere of utility or necessity, according to voluntarily adopted rules. Among the other mandatory parameters of game, they define its voluntary nature, as well as the mandatory rhythm [12].

In the Russian linguistics, "language game" is considered as a form of speech behavior, during which a language personality demonstrates its individual style using its linguistic-creative abilities. L.I. Sapogova finds certain similarities between the notion of "language game" and a specific act of a person's usage of his/her language ability "as a system of potential ideas for experimenting with different language levels in order to identify their new possibilities which allow feeling joyful admiration for the language phenomenon and for being aware of his/her power over it" [13]. According to the researchers, language game involves "conscious manipulation of the language, based both on anomalies and unusual use of language means" [14]. For the goals of the given research, it is essential to emphasize that one of the forms of such language "manipulation" can be "game manipulation" of implicit meanings.

\section{Precedence and Language Game Within the Context of Communicative Triad}

Implicit meanings production according to the language game principle can be performed by including precedent texts in a person's speech. Precedent texts are known to be used for different purposes. Various researchers point out the property of "included texts" to imply axiological meanings, to act as a means of argumentation, to perform a "password" function (G.G. Slyshkin). It seems that precedent text (and precedent phenomena of a different nature as well) can be intentionally included in speech (text) in order to create information deficiency for gaming purposes. In such cases the implicit meanings production is based on the parameter of the existence/lack of precedent text significance for various categories of recipients. Significance is determined by the following facts: the sender consciously produces the reference to the text, he has a presumption of addressee's knowledge of 
this text and, finally, the addressee is able to recognize the reference to this text [15].

One of the typical communicative situations in which the speaker deliberately uses a precedent text with a gaming purpose, namely, to complicate its understanding is the situation of communicative triad. As the authors observe, the communicative triad is organized by at least two heterogeneous categories of message recipients. The latter are traditionally denoted by the term "addressee" [16] and are used to consider communicative situations with two participants -a speaker and a listener without involving the possibility of appearance of third parties in them. Meanwhile, their appearance potentially leads to a wider range of an addressee's communicative roles. Depending on the mode of participation ("planned" or "accidental" addressee), the sender of speech can perceive the category of "addressee" as a number of subcategories, namely: "direct addressee", "indirect addressee", "eavesdropping addressee", "random listener" [17]. Within the context of communicative triad, the addressee's presumption of the text knowledge is complicated by the presumption that the text use is not significant for untargeted recipients.

The appeal to precedent texts concepts and unequal degree of their markedness for different categories of recipients is achieved through indirect inclusions. In such situations the peculiarity of game communication is considered to be different degree of awareness of its participants about the terms and rules of the game. However, a much more important thing here is the fact of unawareness of both the act of the game and the "game" material (symbolic means) used by the party against which the game is played.

Messages with implicit meanings can develop by several scenarios that differ from each other, which corresponds to the two main game forms distinguished in the game theory: game-competition and gamepresentation [18]. The following communicative situation is developed within the framework of the "gamepresentation" scenario. The action takes place in a private hotel, new guests are arriving at it. One of them - Mrs Paget - is a very conservative and a bit stupid woman. The hostess's friend (Ivor) is responsible for receiving and entertaining guests. On the day of Mrs. Paget's arrival Ivor tries to make an impression on her during her first visit to the dining room:

'Ivor came in, looking as though he was swimming in a suit several sizes too big for him. Usually he wore knee breeches and a Norfolk jacket. ... it was very nice of him to make such an effort. He bowed over my hand and kissed it, looking very much the gentleman, if somewhat eccentric. He went to stand by Mrs Paget and asked her how she liked Kent.

'It's rather cold, isn't it?' was all she had to say, in a flat, precise little voice.

'Ah!' "Though art a summer bird, which ever in the haunch of winter sings the lifting up of day."

'Pardon?'. she looked rather offended to be called a bird.' [Clayton V. Past Mischief, 1999].

The intertextual inclusion as a replica fragment from the historical drama King Henry IV by W. Shakespeare that was originally pronounced by the king describes the reaction to the good news brought by Westmoreland:

'King Henry: O Westmoreland, thou art a summer

bird,

Whichever in the haunch of winter sings

The lifting up of day [Clayton V. Past Mischief, 1999].

Ivor tried to develop the topic of "conversation about the weather", and this inclusion based on the figurative association 'a summer bird'- a harbinger of spring ('the lifting up a day'), is a failed compliment that should be interpreted from Ivor's point of view as follows: "The nature itself which will soon reward us with warmth and we are happy with your arrival".

The small talk that is continued in the form of a game with implicit meanings - 'Ivor had worked up a full head of steam' -is based on the literal quotation of Lucius Annaeus Seneca with the direct reference to the source:

'Seneca made an interesting comment about temporal power. 'However many people a tyrant slaughters, he cannot kill his successor.' Obviously when you think of it? But a good point, wouldn 't you say?' - He looked expectantly at Mrs Paget. The participants of the game are the same persons - Ivor and Mrs. Paget, who are not able to recognize intertextual links and meanings generated by them due to the specificity and limitations of her own "reading circle": 'Mrs Paget's reading was confined to the sort of books that go into great detail about whether the little Princess Margaret Rose liked shrimp paste or jam for tea, what comedy turns the Queen Mother enjoyed at the Royal Variety Show and what sort of soap 'Crawfie' used for the infant bath' [Clayton V. Past Mischief, 1999].

It should be noted that gaming manipulation with implicit meanings is most likely a type of communicative behavior of a separate language personality, in this case, of Ivor - a person who loves to use "high style" and receives aesthetic pleasure doing it. The presence of "observers" (guests sitting at the table) and Ivor's presumption regarding their ability to evaluate the very fact of the game and the semantic associations arising during it are highly important:

'Mr Tremlow understood it too, for I saw a ripple of amusement run through the hachure lines on his face as he took up Ivor's question'.

Another game situation of the "presentation" type is associated with the designation of a precedent situation dating back to the reign of Queen Elizabeth I Tudor:

'Mr Tremlow was the perfect guest, and asked me to tell him something of the history of the house. I told all I knew about its first existence as a priory and about the early years in private ownership, in particular that of Margaret le Bec whose arms were above the fireplace in the dining room. He was particularly interested in the letters that had been found behind the panelling upstairs when the Victorian owner of Westray had put in the first bathroom.

'Are they still in the house? I should so much like to see them.'

'The originals are in the local museum but we have copies. I'll show them to you after dinner, if you like.' 
'These letters, now. Tell me about them,' said $\mathrm{Mr}$ Tremlow, helping himself to more pheasant from the dish Jenny offered him.

'Some time after becoming a widow, Margaret le Bec converted to Roman Catholicism. There were several recusant households in this area, probably sharing the responsibility for hiding Catholic clergy. It's clear from the letters that Margaret and the priest, who was her spiritual mentor, became lovers. The letters are very sad, really, all about the imperilling of their immoral souls. She must have been a brave woman. It was no joke being a Catholic in those days.'

'What say ye in answer to the 'Bloody Question?' quioted Ivor.

'Pardon?' Priscilla looked quite fierce.

'Priscilla doesn't like languages,' said Reg.

The game character of the speech behavior is clarified by subsequent explication of intertextual links:

' I was speaking of the interrogation all suspected Catholics had to undergo in the reign of Elizabeth ...

Would you defend England against the Pope if he himself invaded? It's known as the 'Bloody Question

'. Priscilla's pale eyes looked beseechingly at her husband as she tried to get her mind around the concepts involved. 'I don't know,' she said, at last. 'Father didn't like Catholics. He was a Baptist, Strict and Particular.' [Clayton V. Past Mischief, 1999].

Another type of scenario which involves the game with implicit meanings is associated with the idea of "competition". The following example describes the meeting of four gangsters the day before the planned bank robbery. Two of them (Gainer and Leslie) present a pair of lovers and they believe that all their actions are protected by a guardian angel named Lady Caroline. A series of precedent statements - "block quotations" -is developed on the basis of a fictional concept (according to B.M. Gasparov); they are reproduced by them every time before or after dangerous crimes and Lady Caroline guarantees the success: 'Who was it this time, the Lady Caroline? 'You definitely have Lady Caroline to thank.'. The very beginning of the dialogue can be represented in terms of a game situation involving two "opposing parties":

'Hello handicapper,' Chappin greeted him. Vinny merely raised his hand for hello.

'I was just about to call you,' Gainer told them.

'Thought we might not show?' '....

Gainer filled a highball glass with wine, gulped some. 'Any luck with Lady Caroline? J 'For a while,' Leslie told him. - 'She's been in limbo.'

'Great place for a vacation.' - 'Lady Caroline told me to go for it.'

The outcome of the "competition" is considered as a victory won due to the ability of two of its participants to interpret the message within the context of their common possible world, which cannot be understood by the "second side", that is why Lady Caroline becomes real for them as a potential participant in the planned robbery:

Chapin stopped her. 'You didn't mention anyone else in on this' [Browne G.A. Purchase Street, 1983].
In most cases interpreting the precedent inclusion is quite complicated and depends on the degree of its recognition. In the examples analyzed above, the participants use precedent texts known by specific audience. Special precedent phenomena become even more difficult to understand and to interpret.

The next example is a fragment of a conversation between a resuscitation doctor of a US clinic and an official visitor - an FBI officer. The purpose of the visitor is to obtain information about the state of the new patient who is of particular interest to the investigators. Due to lack of time and, possibly, hostility towards the authorities, the doctor tries to ignore the questions asked. However, being forced to give the necessary information, he begins to use the language which is usually spoken only among his "circle". The doctor does not worry about the semantic "transparency" of his message and develops the conversation at the level of "professional - amateur":

'You just brought a woman in,' he told the nearest doctor. 'Moira Wolfe.'

'... She's the OD.'

'She is a person, not a goddamned OD! Murray didn't say.

Instead he nodded. 'Where?' 'You can't ...'

Murray cut him off cold. 'She's part of major case. I want to see what's happening.'

The doctor led him to a treatment cubicle. It wasn't pretty. Already there was a respirator tube down her throat, and IV lines in each arm - on second inspection, one of the tubes seemed to be taking her blood out and running it through something before returning it to the same arm...

'Is she going to make it?' Murray asked.

'Who the hell are you?' a doctor asked without turning. 'FBI, and I need to know'.

The doctor still didn't look around. '... She took Placydil. ... We're dialyzing her blood ... We've put her on hundred-percent oxygen, then we'll zap her full of IV fluids, and wait it out. She'll be out for at least another day. Maybe two, maybe three. Can't tell yet. I can't tell you what the odds are either. Now you know as much as I do. Get out of here. I got work to do.' [Clancy T. Clear and Present Danger, 1989].

The psychological basis of communication at the level of exact representations, as it is indicated in a number of works, is craving for communicative leadership $[19,20]$. In the example mentioned above, there is a combination of two factors that allow for this kind of social domination - predominance of "encyclopedic competence" - the speaker's ability to verbally describe the state of affairs in a given subject area and the speaker's desire to "deal for a fall" with the addressee.

Thus, the above-mentioned means of creating implicit meanings are quite complex, they require that a speaker and a listener have strong skills of developing and recognizing intertextual inclusions. In everyday communication, speakers often use simpler means of playing with meanings, which is achieved, in particular, at the expense of the category of uncertainty.

The following example describes the meeting of mother and daughter (Miranda), here the gaming "text 
protection" (the term of the Volgograd school of linguistic thought) based on intertextual inclusions is complemented by the reference uncertainty:

'Miranda? I suppose it's too much to expect any sort of welcome,' came the well-known tones of my mother. 'One drags oneself half-way across Europe for the sake of one's children and what thanks does one get? Shakespeare knew it all, of course ...How very much sharper than a serpent's tooth!'

The quasi-Lear was standing in the hall while a rebellious-looking taxi-driver was bringing in several expensive suitcases.' [Clayton V. Past Mischief, 1999].

There is uncertainty of reference based on the deliberate use of the word combination one of us in the following example as well:

'Poor Bear stretched out a paw, and Rabbit pulled and pulled and pulled...'

'Ow!' cried Pooh. 'You're hurting!'

'The fact is', said Rabbit, 'you're stuck.'

'It all comes' said Pooh crossly, 'of not having front doors big enough.'

'It all comes, 'said Rabbit sternly, 'of eating too much. I thought at the time, said Rabbit, 'only I didn't like to say anything' said Rabbit, 'that one of us has eaten too much,' said Rabbit, 'and I know it wasn't me, 'he said. [Milne A.A. Winnie-the-Pooh, 1926].

\section{Conclusion}

Summing up the ideas of implicit mechanisms, it should be noted that implicit meanings arise on the basis of explicitly expressed meanings and interactions with context, speech situation, or some other significant background. The gaming ways of creating implicit meanings described above are based on using precedent texts in speech and they develop according to two basic scenarios "game-competition" and "game-presentation". These methods are found both alone and in combination with the other ones, in particular, with using the category of uncertainty for game purposes. In this cases a sender of the message plays an active part, since it is he who acts as a kind of "organizer of understanding". Regardless of the purpose and method of producing implicit meanings all of them can be referred to one of the types of "indirect communication".

\section{References}

1. A.A. Zaliznyak, Questions of linguistics, The Phenomenon of Ambiguity and Ways to Describe it, 2, 20-45 (2004)

2. Reboul, Pragmatics at its Interfaces, Is implicit communication a way to escape epistemic vigilance?, 17, 91-112 (2017)
3. A. Capone, Indirect Reports and Pragmatics in the World Languages, On the social praxis of indirect reporting, 19, 3-20 (2019)

4. D.S. Kondrashova, Text Processing and Cognitive Technologies: Collected papers (Materials of the VIII International Conference 'Cognitive Modeling in Linguistics'), To the Problem of Classifying Types of Implicit Information, 11 (1), 245-252 (2006)

5. I.I. Prosvirkina, OSU Bulletin, "ImplicitMeanings" of Verbal Communication, 11 (147), 116-119 (2012)

6. N. Fairclough, Language and Power (Longman, London, 1989)

7. R. Wodak,, Discourse as Social Interaction, Critical Discourse Analysis 2, 259-284 (1997)

8. V.I.Karasik, Language of Social Status (Institute of Linguistics, USSR Academy of Sciences, Volgograd Pedagogical Institute, Moscow, 1991)

9. S. Shabat-Savka, Psycholinguistics, Psycholinguistic Dimension of Communicative Intention: Speaker's Substance and Syntaxing, 24 (2), 321-339 (2017)

10. R. Sasamoto, D. Wilson, Lingua, Little Words: Communication and procedural meaning Introduction, 175, 1-4 (2017)

11. H.-G. Gadamer, Truth and Method (Progress, Moscow, 1988)

12. J. Huizinga, Homo Ludens. Articles on the History of Culture (Progress-Traditsiya, Moscow, 1997)

13. I.L. Sapogova, Proceedings of Tula State University. Series: Psychology, Components of Language Game and Their Role in Creating Comic Effect, 3, 215-224 (2003)

14. V.Z Sannikov, The Russian Language in the Mirror of the Language Game (Languages of Slavic culture, Moscow, 2002)

15. G.G. Slyshkin, From Text to Symbol: Linguocultural Concepts of Precedent Texts in Consciousness and Discourse (Academia, Moscow, 2000)

16. R.O. Jacobson, Linguistics and Poetics. Structuralism: Pros and Cons: Collection of Articles (Progress, Moscow, 1987)

17. H.H. Clark, Speech Acts and Hearer's Beliefs. Mutual Knowledge (Academic Press, London, 1982)

18. Sigov, Game. Modern Western Philosophy (Politizdat, Moscow, 1991)

19. V. Tsakona, Lingua, Intertextuality and/in political jokes, 203, 1-15 (2018)

20. H. Zhang, H. Ma, Perspectives-studies in Translation Theory and Practice, Intertextuality in retranslation, 26, 576-592 (2018) 